\title{
Zooplankton biomass dynamics in oligotrophic versus eutrophic conditions: a test of the PEG model
}

\author{
DIETMAR STRAILE \\ Limnological Institute, University of Konstanz, Konstanz, Germany
}

\begin{abstract}
SUMMARY
1. The model of the International Society of Limnology (SIL) Plankton Ecology working group (hereafter the PEG model) is a verbal model describing the patterns and driving factors of seasonal phytoplankton and zooplankton succession in oligotrophic and eutrophic lakes (Sommer et al., 1986). Despite being a citation classic, tests of the PEG model with respect to differences in zooplankton biomass dynamics between oligotrophic and eutrophic lakes are lacking.

2. Here, I use the long-term data from Lake Constance, which during the last 100 year changed from an (ultra-) oligotrophic lake to a eutrophic lake and back to an oligotrophic lake to analyse trophic status differences in zooplankton biomass seasonality. Using data from one lake allows one to study trophic influences on biomass dynamics without the confounding effects of lake geographical setting and lake morphology, which complicate comparative dynamics in eutrophic versus oligotrophic lakes. However, environmental changes due to other driving factors, for example climate change, may possibly alter biomass dynamics as well.

3. Data from Lake Constance do not support the differences in zooplankton seasonality in respect to peak timing between eutrophic and oligotrophic lakes suggested by the PEG model. Rather total zooplankton biomass, as well as cladoceran and copepod biomass showed a peak in May/June during all trophic conditions. Biomass dynamics of cladocerans during spring were more strongly influenced by water temperature than by trophic state. Furthermore, analyses of the geographical setting of the lakes considered in Sommer et al. (1986) suggest that the proposed differences in zooplankton seasonality between eutrophic and oligotrophic lakes are at least partially due to the confounding effect of lake altitudinal setting; the oligotrophic lakes were located at higher altitude than the eutrophic lakes.

4. As a consequence of the results from Lake Constance, and the bias detected in the Sommer et al. (1986) study, a modified PEG model is proposed which considers low water temperature and not food limitation as the most important factor reducing zooplankton growth rate during early spring in both oligotrophic and eutrophic lakes.
\end{abstract}

Keywords: cladocerans, copepods, plankton succession, temperature, trophic state

\section{Introduction}

Since its publication, the PEG model (Sommer et al., 1986) has developed into a classic of plankton ecology surpassing 1000 citations in the Web of Science in 2013. The verbal model and the sketch of the seasonal dynamics of phytoplankton and zooplankton in temperate lakes are found in many textbooks (Lampert \& Sommer, 1993; Wetzel, 2001; Dodson, 2004) and recently were updated in respect to processes crucial for plankton succession not considered in the original publication (Sommer et al., 2012) and to more northern and southern climatic regions (De Senerpont Domis et al., 2013).

One important pattern identified by the PEG model is the difference in the seasonal dynamics of phytoplankton and zooplankton between eutrophic and oligotrophic lakes. While the proposed differences in seasonal patterns have been tested rigorously for phytoplankton

Correspondence: Dietmar Straile, Limnological Institute, University of Konstanz, 78464 Konstanz, Germany.

E mail: dietmar.straile@uni konstanz.de 
dynamics (Marshall \& Peters, 1989), differences in zooplankton dynamics between eutrophic and oligotrophic lakes remain largely untested and remain unchanged in recent updates of the PEG model. The key difference in the seasonality between eutrophic and oligotrophic lakes is suggested to be due to the peak timing of zooplankton biomass, which is proposed to take place in eutrophic lakes considerably earlier than in oligotrophic lakes, because of strong food limitation of zooplankton in oligotrophic lakes during the growth period (Sommer et al., 1986).

However, recent work on climate impacts on Daphnia seasonal dynamics has highlighted that spring phenology is strongly determined by spring water temperature (Gillooly \& Dodson, 2000; Straile, Adrian \& Schindler, 2012). 57\% of phenological variability in 49 lakes/sites of varying trophy and morphometry across the Northern Hemisphere is explained by a seasonal water temperature isotherm (Straile et al., 2012). Furthermore, Daphnia phenology in three lakes undergoing strong reductions in phosphorus concentrations was not delayed because of the shift from hypertrophy to eutrophy or eutrophy to oligotrophy (Straile et al., 2012). Rather phenological variation within and across the three lakes was also due to isotherm variation. These results are corroborated by a modelling study which suggests that an almost 10-fold variation in algal carrying capacity shifted Daphnia phenology by only 25 day, whereas Daphnia phenology was advanced by 54 day due to a 60-day earlier onset of vernal warming (Schalau et al., 2008).

As Daphnia is an important component of zooplankton biomass, it is unclear how the results on Daphnia phenology can be reconciled with the predictions of the PEG model concerning the differences in zooplankton biomass seasonality between eutrophic and oligotrophic lakes. However, the relative contributions of different zooplankton groups are known to change with nutrient concentration (Pace, 1986; Straile \& Geller, 1998). For example, the relative importance of copepods increases and the relative importance of cladocerans decreases with decreasing nutrient concentrations. Hence, the dominant role of temperature relative to trophic status in determining cladoceran phenology may be reconciled with the PEG predictions for total zooplankton if cladocerans dominate seasonal biomass dynamics in eutrophic lakes and copepods possibly with a biomass maximum later in the season dominate seasonal biomass dynamics in oligotrophic lakes.

There are two approaches to test this hypothesis: (i) assembling a data set with crustacean seasonal biomass dynamics in many oligotrophic and eutrophic lakes and controlling for the effects of among-lake temperature variation due to, for example, different depths and the altitudinal and latitudinal setting of the lakes and (ii) following seasonal biomass dynamics in a lake before and after a switch from oligotrophy to eutrophy or vice versa. Here, I use the second approach and analyse zooplankton dynamics in Lake Constance, which due to phosphorus pollution has shifted in the last century from a presumably (ultra-) oligotrophic to a eutrophic state and was returning to an oligotrophic state during the last three decades (Jochimsen, Kümmerlin \& Straile, 2013) as a result of massive investment in sewage treatment (Güde, Rossknecht \& Wagner, 1998). I compare seasonalities of crustacean community composition, of total crustacean biomass, cladoceran biomass as well as copepod biomass in different time periods representing different trophic status of Lake Constance and analyse whether the change of trophic conditions has resulted in a change of zooplankton biomass seasonality proposed by the PEG model.

\section{Study site and methods}

Lake Constance is a deep $\left(z_{\max }=252 \mathrm{~m}\right)$ warm-monomictic lake at the northern fringe of the Alps. Complete ice cover is a rare event and occurred the last time during the winter 1962/63. Interannual water temperature variability is linked to the North Atlantic Oscillation (Straile, 2000), and the response to climate warming is characterised by a step-wise increase of water temperatures in 1988 (Jochimsen et al., 2013). At the beginning of the 20th century, Lake Constance was considered as an archetype of an oligotrophic lake (Thienemann, 1921). The first measurements of phosphorus performed in the 1930s supported this classification, that is phosphorus concentrations never exceeded detection levels (Elster \& Einsele, 1937). Although diatom remains in the sediment suggest slight eutrophication already in the first half of the 20th century (i.e. decreasing relative importance of Cyclotella species, Wessels et al., 1999), strong eutrophication started after the 1950s with total phosphorus concentrations during winter overturn $\left(\mathrm{TP}_{\mathrm{MIX}}\right)$ exceeding $10 \mu \mathrm{g} \mathrm{L}^{-1}$ after the mid-1950s. Maximum $\mathrm{TP}_{\mathrm{MIX}}$ was observed at the end of the 1970s $\left(87 \mu \mathrm{g} \mathrm{L}^{-1}\right.$ during winter overturn 1978/79), and declined rapidly thereafter (Güde et al., 1998). After 2003, TP $\mathrm{MIX}$ was again below $10 \mu \mathrm{g} \mathrm{L}^{-1}$, and in recent years, values typical for the early 1950s (6 $10 \mu \mathrm{g} \mathrm{L}^{-1}$ ) were observed. Diatom community composition in the sediment also suggests that the trophic status in recent years is similar to that of the 
early 1950s, but more eutrophic than in the 1920/1930s (N. Albrecht, unpublished data).

In this study, I compare the biomass dynamics of zooplankton in Lake Constance within three 5-year periods: 1920 24, 197984 (excluding 1983 as no data were available) and 2008 12. According to total phosphorus measurements and the trophic history of the lake (see above), these time periods represent putatively (ultra-) oligotrophic conditions (1920 24, no TP measurements available, but in the 1930s, phosphorus was below detection level (Elster \& Einsele, 1937), eutrophic conditions (1979 84, mean $\mathrm{TP}_{\mathrm{MIX}}=81 \mu \mathrm{g} \mathrm{TP} \mathrm{L}^{-1}$ ) and oligotrophic conditions (2008 12, mean $\left.\mathrm{TP}_{\mathrm{MIX}}=7 \mu \mathrm{g} \mathrm{TP} \mathrm{L}^{-1}\right)$. During the (ultra-) oligotrophic period, zooplankton was sampled using a Nansen closing net at approximately monthly intervals by Auerbach, Maerker \& Schmalz (1926). In the oligotrophic and eutrophic periods, a Clarke-Bumpus sampler was used to collect zooplankton at weekly intervals during the stratified period and less regularly during the winter months (Straile \& Geller, 1998). Conversion of abundance estimates to biomass was performed as specified in Straile \& Geller (1998).

Sampling after 1979, that is during the oligotrophic and eutrophic periods, was performed in the Überlinger See, a fjordlike, north-western extension of Upper Lake Constance. In the (ultra-) oligotrophic period, zooplankton was collected at a multitude of sampling points in Upper Lake Constance, that is including Überlinger See. However, this difference in sampling area is unlikely to affect the conclusions of this study, as a 14-year study analysing zooplankton at five sites (including Überlinger See) in Upper Lake Constance showed that with the exception of the shallow Bay of Bregenz located in the eastern part of Upper Lake Constance, seasonal dynamics of zooplankton composition and abundance were remarkably similar (Seebens, Einsle \& Straile, 2013). Zooplankton sampling and enumeration in the (ultra-) oligotrophic period differed from the other two sampling periods also in respect to sampling depth and differentiation into size classes. In the (ultra-) oligotrophic period, zooplankton size classes were not distinguished and the layer between 0 and $50 \mathrm{~m}$ was sampled, whereas in the two other periods, up to five size classes were distinguished for each zooplankton species (see Straile \& Geller, 1998) and the layer between 0 and $140 \mathrm{~m}$ was sampled.

The consequences of methodological differences between the (ultra-) oligotrophic period and the two other periods were investigated with sensitivity analyses. The effects of zooplankton enumeration were tested via computing zooplankton biomass composition and seasonalities for the periods 197984 and 200812 using species-specific dry masses as for the period 192024 , that is ignoring size classes. The vast majority of zooplankton resides at depths $<50 \mathrm{~m}$ in Lake Constance (Muckle \& Muckle-Rottengatter, 1976; Geller, 1986). However, according to Muckle \& Muckle-Rottengatter (1976), zooplankton sampling within the upper $50 \mathrm{~m}$ will underestimate the summer abundance of one species, that is Heterocope borealis up to $\sim 20 \%$. The consequences of Heterocope abundance underestimation for seasonality of total zooplankton biomass were calculated by, assuming that Heterocope abundances were underestimated by a factor of two from June onwards. Finally, sampling nets may differ in their efficiency to collect different zooplankton species (De Bernardi, 1984). Because it is unclear whether and for which species the Nansen closing net of Auerbach, Maerker \& Schmalz (1924), Auerbach et al. (1926) differs from the Clarke-Bumpus sampler, I used a randomisation approach to analyse the consequences of species-specific sampling efficiencies for total crustacean biomass seasonality during the period 1920 24: Calculation of biomass seasonalities was repeated 500 times based on abundance estimates accounting for species-specific sampling efficiencies. For each reiteration, a sampling efficiency of 25, 50 or $100 \%$ was randomly assigned to each species before calculation of biomass seasonality.

As only monthly resolution exists for the (ultra-) oligotrophic period, data for the other two periods were aggregated to monthly means prior to analyses. For each time period, the relative contribution of nine taxa (Eudiptomus gracilis, Heterocope borealis, cyclopoid copepods, Daphnia longispina (former D. hyalina), Daphnia galeata, Bosmina spp., Diaphanosoma brachyurum, Leptodora kindtii, Bythotrephes longimanus) to biomass in each month was calculated. Biomass seasonality was examined at three levels of aggregation: total copepod biomass, total cladoceran biomass and total crustacean biomass. As zooplankton sampling methods differed between the time periods, biomasses were standardised within each period by subtracting the period mean from an individual monthly biomass estimate and then dividing the difference by the period standard deviation.

May temperatures have been shown to be crucial for spring biomass dynamics of Daphnia in Lake Constance (Straile, 2000). As water temperatures have increased during the last decades (Jochimsen et al., 2013), I analysed the influence of May water temperatures on zooplankton biomass for the time period from 1979 to 2012. Unfortunately, it was not possible to retrieve reliable water temperatures for the period 192024 from the 
original publications (Auerbach et al., 1924; Auerbach et al., 1926). Water temperatures after 1979 were measured either continuously via thermistor chains or with temperature probes at weekly time intervals (Straile et al., 2012). To test the influence of temperature on zooplankton biomasses, mean May temperatures within the upper $20 \mathrm{~m}$ of the water column as well as TP $\mathrm{MIX}$ values were used as independent variables in multiple regression models to predict cladoceran, copepod and total crustacean biomass in May.

\section{Results}

Community composition of crustacean zooplankton differed strongly between the three periods (Fig. 1). During the (ultra-) oligotrophic period, biomass was dominated by Eudiaptomus gracilis, with the exception of summer months when Daphnia longispina contributed up to almost $40 \%$ and Heterocope borealis up to c. $20 \%$ to total biomass (Fig. 1a). During the winter months, Bosmina spp. and cyclopoid copepods comprised c. $20 \%$ of the total biomass, whereas contributions of other taxa never exceeded $10 \%$ of total crustacean biomass.

During eutrophication, Heterocope borealis and Diaphanosoma brachyurum disappeared and D. galeata invaded the lake (Fig. 1c). The contributions of D. galeata in late spring and early summer were as high as those of $D$. longispina, resulting in contributions of daphnids to overall biomass from $>40$ to $<80 \%$ from June to November. Between February and May, the relative share of cyclopoid copepods strongly increased relative to Eudiaptomus. Biomass composition in the oligotrophic period differed from the eutrophic period, especially in regard to cladocerans (Fig. 1b). Diaphanosoma re-invaded the lake and contributed during late summer and autumn to overall biomass, albeit with a lesser share than during the (ultra-) oligotrophic period, and D. galeata strongly decreased. However, the total share of daphnids remained relatively high due to an increase of D. longispina. As in the eutrophic period, cyclopoid copepods contributed more to overall biomass than Eudiaptomus from February until June.

Total crustacean biomass showed a maximum in the eutrophic and (ultra-) oligotrophic periods in June and during the oligotrophic period in May (Fig. 2). In contrast to the other two periods, the (ultra-) oligotrophic period was also characterised by a pronounced second biomass maximum in October (Fig. 2). Both cladoceran and copepod biomass showed a spring/early summer biomass peak in all three time periods (Fig. 3 ). In the (ultra-) oligotrophic period, copepod biomass peaked in May and cladoceran biomass peaked in June, and both groups contributed almost equally to the maximum total biomass in June. In contrast, during the October, maximum copepod biomass exceeded cladoceran biomass. In the eutrophic period, cladoceran biomass was at its maximum in June/July, whereas the copepod biomass maximum was in May. In the oligotrophic period, the biomass maximum of cladocerans, but not that of copepods, advanced by 1 month. In both the eutrophic and the oligotrophic periods, the late spring/early summer biomass maximum was dominated by cladocerans.

The patterns shown in Figs 13 are robust regarding whether zooplankton was or was not separated into distinct size classes. Ignoring size class distinctions for the eutrophic and oligotrophic periods and calculating biomasses with a taxa-specific mean dry mass per individual did not result in shifts of the biomass peak from late spring to mid-summer (Figs S2 and S3). However, biomass seasonality based on zooplankton size classes (a) (Ultra ) oligotrophic
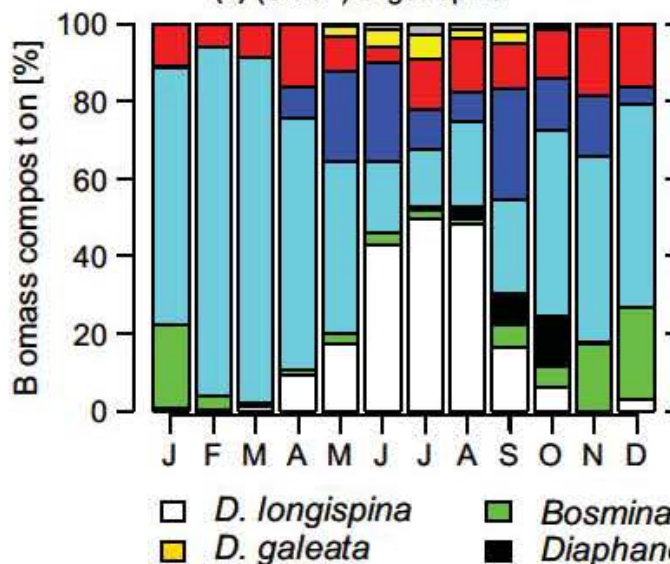

(b) Oligotrophic

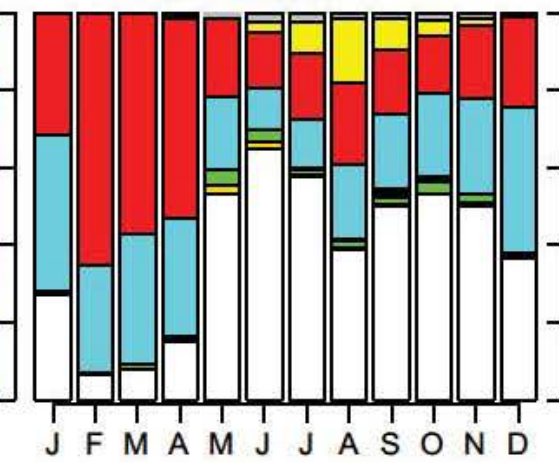

$\square$ Eudiaptomus (c) Eutrophic

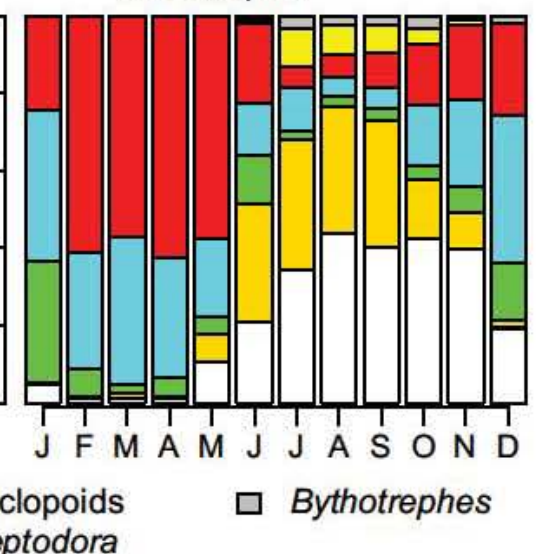

Fig. 1 Crustacean biomass composition during the (a) (ultra ) oligotrophic, (b) oligotrophic and (c) eutrophic periods of Lake Constance. 


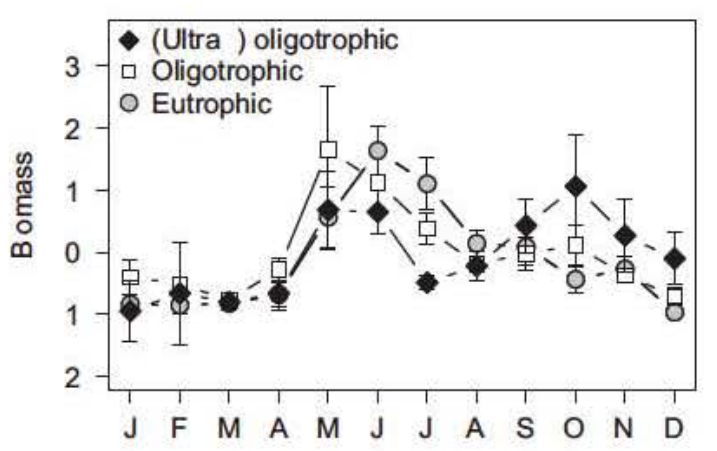

Fig. 2 Standardised biomass dynamics of total crustacean biomass during the (ultra ) oligotrophic, oligotrophic and eutrophic periods of Lake Constance. Error bars present \pm one standard error.

resulted in a spring peak distributed over 2 month in both the eutrophic (June and July) and oligotrophic (May and June) periods (Figs $2 \& 3$ ), whereas when no size classes were considered, the spring peak was more clearly confined to 1 month (May in the oligotrophic period and June in the eutrophic period) (Figs S2 and S3). This is because earlier in the season, smaller individuals (juveniles) contribute more strongly to the populations than 1 month later. Likewise, the patterns shown are robust in respect to differences in sampling depths between the study periods. Even a twofold underestimation of biomasses after June of those species performing diel vertical migration partially below $50 \mathrm{~m}$ depth (Heterocope borealis) did not strongly alter biomass seasonality in the period 192024 (Fig. S4). Finally, species-specific sampling efficiencies will also not change the basic pattern of biomass seasonality during 192024 consisting of a biomass peak during May/June, lower biomasses in July/August and an autumn peak (Fig. S5a). In all realisations of randomly assigned sampling efficiencies, mean May/June biomasses were larger than mean July/August biomasses (Fig. S5b).

May water temperatures in the oligotrophic period were $2.3 \pm 0.5^{\circ} \mathrm{C}$ higher than May temperatures in the eutrophic period $\left(F_{18}=23, P<0.002\right)$. Figure 4 shows the univariate relationships between May water temperatures and the May biomasses of cladocerans, copepods and total crustaceans during the period 1979 2012. These scatter plots suggest a strong influence of May temperatures on cladoceran biomass, no influence on copepod biomass and a weak influence on total crustacean biomass. However, multiple regression analyses with May temperatures and $\mathrm{TP}_{\mathrm{MIX}}$ as independent variables suggest that all three biomasses were significantly related to May temperatures and $\mathrm{TP}_{\mathrm{MIX}}$ (Table 1). The slope for the cladoceran relationship with May temperatures was much steeper than the one for copepod biomass with (a)

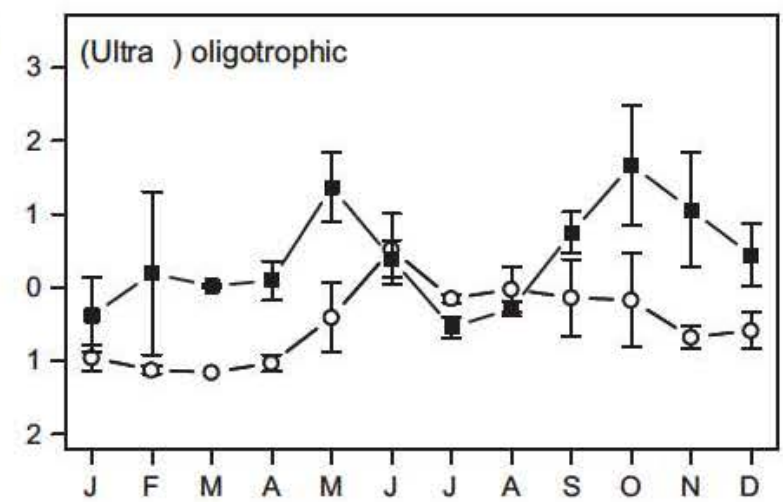

(b)

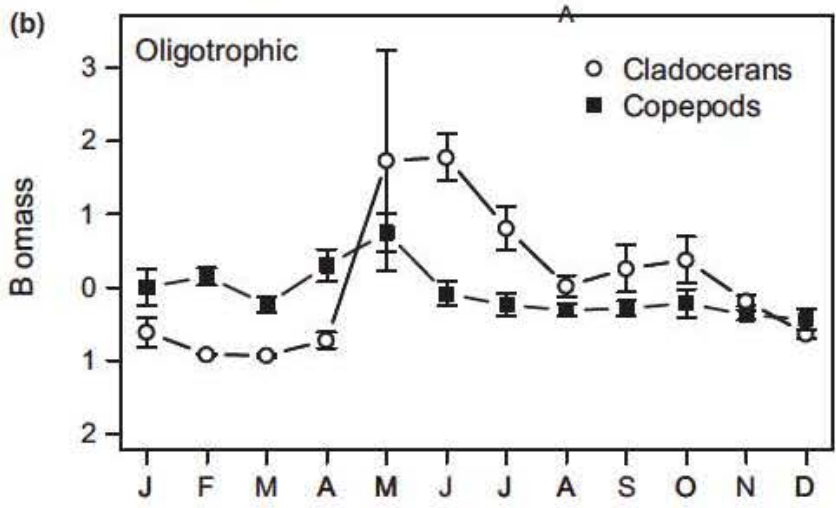

(c)

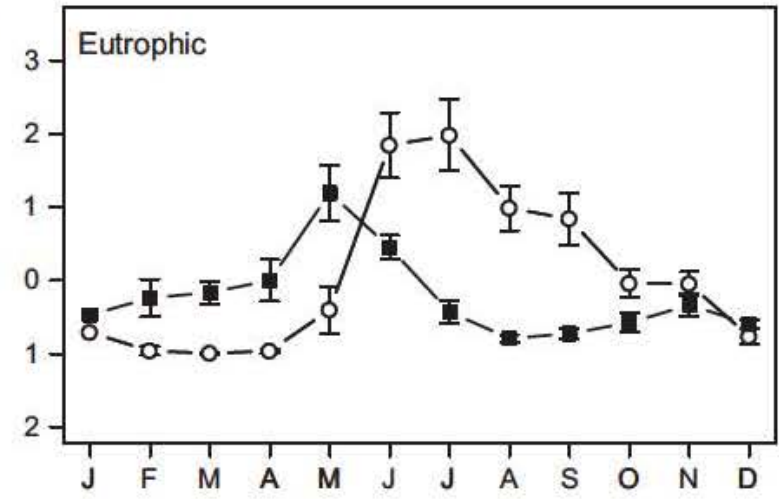

Fig. 3 Standardised biomass dynamics of cladocerans and cope pods biomass during the (a) (ultra ) oligotrophic, (b) oligotrophic and (c) eutrophic periods of Lake Constance. Error bars pres ent \pm one standard error.

May temperatures, whereas in respect to the slopes with $\mathrm{TP}_{\mathrm{MIX}}$, cladocerans and copepods did not differ (Table 1).

\section{Discussion}

Data from Lake Constance do not support the differences in biomass seasonality between eutrophic and oligotrophic conditions proposed by the PEG model (Sommer et al., 1986). During both eutrophic and oligotrophic conditions, total crustacean zooplankton, as well as cladoceran and copepod biomass peaked in late spring/early summer. This conclusion does not rely on 
Fig. 4 Relationship between May water temperatures in the upper $20 \mathrm{~m}$ of the water column and May biomasses of a) cladocerans, b) copepods and c) total crustaceans during 19792012 (no data available for 1983). The eutrophic years (1979 84) are shown as white circles, oli gotrophic years (2008 12) as black, all other years (1985 2007) as grey circles. The lines represent least square fits between biomasses and temperatures, continuous line: $P<0.01$, broken line: $P<0.1$.

the inclusion of the (ultra-) oligotrophic period and is thus not affected by methodological differences in sampling methods between the (ultra-) oligotrophic period and the two other periods.

The biomass peak of copepods was not later than that of cladocerans. Indeed, if there is any difference between taxa, the biomass peak of copepods in Lake Constance was earlier compared to the biomass peak of cladocerans during the eutrophic, oligotrophic and (ultra-) oligotrophic periods. An earlier spring peak of cyclopoid and calanoid copepods compared to cladocerans was, for example, also reported in experimental mesocosms analysing warming and browning effects on zooplankton phenology (Nicolle et al., 2012). Hence, the increase in relative importance of copepods from eutrophy towards oligotrophy is unlikely to result in a delay of the total crustacean spring biomass peak.

The cladoceran spring peak was not delayed in (ultra-) oligotrophic and oligotrophic periods as compared to the eutrophic period. In contrast, the spring peak was earliest in the oligotrophic period, which is likely a result of increased water temperatures in Lake Constance due to global warming (Straile, Jöhnk \& Rossknecht, 2003; Straile et al., 2012; Jochimsen et al., 2013). The strong relationship between May cladoceran biomass and May water temperatures, despite oligotrophication, supports previous work showing that spring
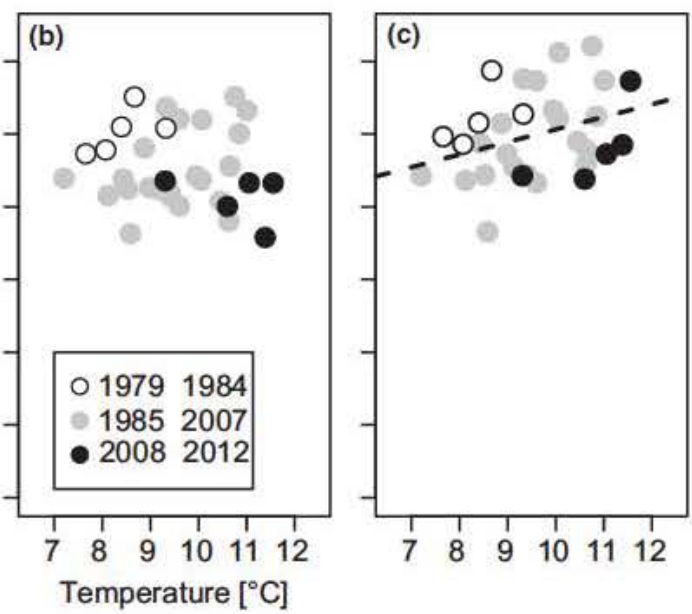

dynamics of cladocerans are predominantly influenced by water temperature (Gillooly \& Dodson, 2000; Straile \& Müller, 2010; Straile et al., 2012), and only to a lesser degree by food availability (Schalau et al., 2008).

For copepods, the influence of water temperatures on May biomass seems to be less strong compared to cladocerans, which is presumably due to their complex life cycles and long ontogenetic development (Reid \& Williamson, 2010). This could explain why the cladoceran peak was earlier in the oligotrophic period compared to the eutrophic period, but not the copepod peak. Copepod species have life cycle strategies which enable them to exploit the phytoplankton spring bloom. For example, the calanoid copepod Eudiaptomus gracilis is able to overwinter in the plankton in relatively high numbers, allowing use of the phytoplankton spring bloom to increase reproductive output (Seebens et al., 2007). Likewise the cyclopoid copepod Cyclops vicinus emerges from diapause before the onset of the spring phytoplankton bloom and starts to reproduce with the onset of the phytoplankton bloom (Seebens, Einsle \& Straile, 2009). Hence, such species-specific adaptations to exploit the phytoplankton spring bloom seem to result in a spring peak of copepod biomass in Lake Constance, independently of changes in copepod relative biomasses and species inventory. This suggests that despite the diversity of copepod life cycle strategies, a biomass maximum

Table 1 Results of multiple regression models of $\log _{10}$ transformed average May biomasses of cladocerans, copepods and total crustaceans biomass and May water temperatures and total phosphorus during winter overturn ( $\mathrm{TP}_{\mathrm{MIX}}$ )

\begin{tabular}{|c|c|c|c|c|c|}
\hline & \multicolumn{2}{|c|}{ Temperature } & \multicolumn{2}{|l|}{$\mathrm{TP}_{\mathrm{MIX}}$} & \multirow[b]{2}{*}{ Adj $R^{2}$} \\
\hline & estimate & $t$ value & estimate & $t$ value & \\
\hline Cladocerans & $0.377(0.09)$ & $4.19(* * *)$ & $0.007(0.004)$ & $1.83(-)$ & 0.33 \\
\hline Copepods & $0.008(0.04)$ & $2.15(*)$ & $0.008(0.002)$ & $4.86(* * *)$ & 0.40 \\
\hline Crustaceans & $0.175(0.04)$ & $3.93(* * *)$ & $0.007(0.002)$ & $3.82(* * *)$ & 0.36 \\
\hline
\end{tabular}

Significance levels are coded as: $(-) P<0.1,(*) P<0.05$, (***) $P<0.001$. 
of copepods during the spring bloom should be expected in other oligotrophic lakes. Nevertheless, there is a need for more data on copepod biomasses from other lakes to test the extent to which the results from Lake Constance concerning trophic state dependency of copepod seasonal biomass dynamics can be generalised. For example, copepod biomass seasonality after the spring peak in Lake Constance seems to differ between the oligotrophic and (ultra-) oligotrophic periods. With data from only one lake, it is not possible to determine whether this difference is due to trophic state or a secondary effect due to changes in copepod species composition.

In the PEG model, the proposed difference between oligotrophic and eutrophic lakes was based on its contributors knowledge regarding seven eutrophic (maximum TP between 80 and $350 \mu \mathrm{g} \mathrm{L}^{-1}$ ) and six oligo-/ mesotrophic (maximum TP between 9 and $20 \mu \mathrm{g} \mathrm{L}^{-1}$ ) lakes (table 1 in Sommer et al., 1986). The TP concentrations in the study lakes, considered as oligo-/mesotrophic, exceeded the TP levels of the (ultra-) oligotrophic and oligotrophic periods of Lake Constance. Hence, according to TP levels and the PEG model, and contrary to the data presented in this study, the biomass peak in oligotrophic Lake Constance should be shifted more towards summer compared to the oligo-/mesotrophic lakes in Sommer et al. (1986). It needs to be recognised that at the time the PEG model was established, most of the well-studied European lakes were still eutrophied and well-studied oligotrophic lakes were mostly confined to more remote settings, that is to higher altitudes and/or latitudes. This suggests that the eutrophic and oligotrophic lakes considered in Sommer et al. (1986) most likely differed not only in respect to trophic status, but also in altitude and/or latitude and consequently in their temperature regime. Examination of the geographical settings of the 13 lakes reveals that altitude of the six oligotrophic lakes was on average $521 \mathrm{~m}$ above that of the seven eutrophic lakes, whereas there was no significant difference in average latitude (Fig. 5). According to Straile (2002), timing of the clearwater phase, which usually is due to high Daphnia biomass and Daphnia overexploitation of algae (Lampert et al., 1986), is delayed 4 days per $100 \mathrm{~m}$ increase in altitude. Hence, the clear-water phase in the oligotrophic lakes in Sommer et al. (1986) should occur 21 day after the clear-water phase in their eutrophic lakes. Assuming that the timing of the clear-water phase is correlated with the timing of the zooplankton maximum suggests that confounding climatic variation due to the altitudinal setting of the lakes at least partially resulted in the

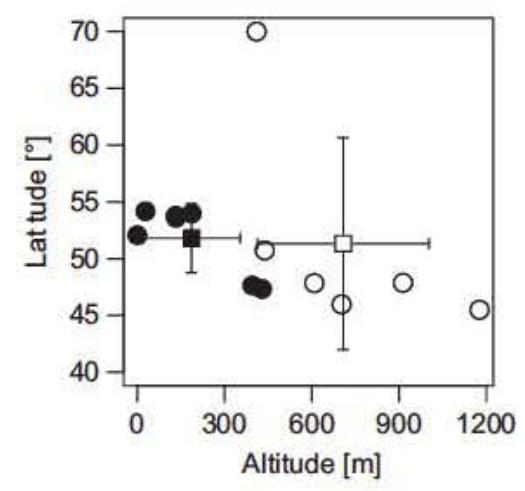

Fig. 5 Geographical setting of the oligotrophic (open symbols) and eutrophic (filled symbols) lakes considered in Sommer et al. (1986).

proposed differences in zooplankton seasonality between eutrophic and oligotrophic lakes in the PEG model.

The revised seasonality in zooplankton biomass during oligotrophic conditions has important consequences for the mechanistic understanding of zooplankton dynamics in both oligotrophic and eutrophic lakes. The original PEG model identified physical factors, predation and food limitation as the principal regulators of zooplankton seasonality (Sommer et al., 1986 their figs 6 \& 7), suggesting that in oligotrophic conditions, food limitation is a strong limiting factor from the beginning of the year up to shortly before the phytoplankton peak, whereas physical factors are more important during autumn and winter. A similar depiction of the seasonality of driving forces is given in the updated version of the PEG model (Sommer et al., 2012; their fig. 2). Unfortunately, putatively important drivers of metazoan zooplankton seasonality, such as temperature, were not included in the updated version of the PEG model, despite many studies highlighting the importance of temperature for zooplankton spring phenology (Gillooly \& Dodson, 2000; Straile et al., 2012). In particular, the PEG model should be modified by including the role of temperature in regulating zooplankton seasonality during winter, and especially during spring in both eutrophic and oligotrophic lakes (see also Berger et al., 2014). Furthermore, data from Lake Constance presented here suggests that the role of food limitation during spring, that is after the onset of the phytoplankton spring bloom, as a driver for zooplankton seasonality has been overestimated in the PEG model. As a result of these changes in the relative importance of forcing factors, the biomass peak of metazoans should not be expected to shift strongly when moving from eutrophic to oligotrophic conditions. Likewise, this change in the relative importance of food versus temperature in regulating zooplankton growth dynamics is 
important with respect to the prediction of global warming effects. For example, according to Sommer et al. (1986), warming should not shift the zooplankton peak in oligotrophic lakes due to strong food limitation (see also De Senerpont Domis et al., 2013). However, the importance of temperature for spring zooplankton dynamics in oligotrophic lakes suggests that warming will advance the spring peak of zooplankton almost as strongly as in eutrophic lakes.

While a stronger control by temperature as compared to food limitation of zooplankton spring dynamics might be expected from previous studies on Daphnia dynamics (Gillooly \& Dodson, 2000; George, 2012; Straile et al., 2012; Wagner et al., 2013), the absence of a clear effect of trophic status on biomass peak timing seems at first surprising. Although modelling (Schalau et al., 2008) and mesocosm (Berger et al., 2007, 2010) studies support the importance of food limitation on Daphnia spring phenology, in addition to the effect of temperature, these studies addressed the effect of food limitation, rather than the effect of trophic status of the lake. While food limitation might be higher in an oligotrophic compared to a eutrophic lake during the spring growth period, zooplankton mortality due to fish and invertebrate predators in oligotrophic lakes is also likely lower than in eutrophic lakes (Sommer et al., 2012). Simulation results have shown that changes in mortality rates can have a strong impact on Daphnia phenology (Schalau et al., 2008). Consequently, reduced zooplankton mortality in oligotrophic conditions is expected to advance the zooplankton biomass peak, which should partially compensate any delaying effects of increased food limitation on peak timing under oligotrophic conditions. The modified view of the dynamics of plankton succession and of its control via physical factors, bottom-up and top-down control in eutrophic and oligotrophic temperate lakes is highlighted in a modified sketch of the PEG model (Fig. 6). It differs from the original PEG model in respect to the biomass dynamics of zooplankton in oligotrophic conditions and by highlighting that physical control of zooplankton (due to low water temperatures) is longer than that of phytoplankton (primarily due to low light availability because of ice cover or deep mixing). As in the original version of the PEG model, the seasonality of controlling factors is presented in a simplified way. In addition, there are important differences in the relative importance of controlling factors among lake types. For example, physical forcing of phytoplankton during winter in shallow ice-free lakes is probably less important compared to deep lakes or in ice-covered lakes where deep mixing or ice cover results in light limitation and a delayed onset of the spring bloom (Weyhenmeyer,
Fig. 6 Sketch of the seasonal biomass dynamics of phytoplankton and zoo plankton and the most important control ling factors under eutrophic (left column) and oligotrophic (right column) condi tions. In the upper panel, phytoplankton biomass dynamics and controlling factors are given and zooplankton biomass is indicated as a hatched line. In the lower panel, zooplankton biomass dynamics and controlling factors are given and phytoplankton biomass is indicated as a hatched line.

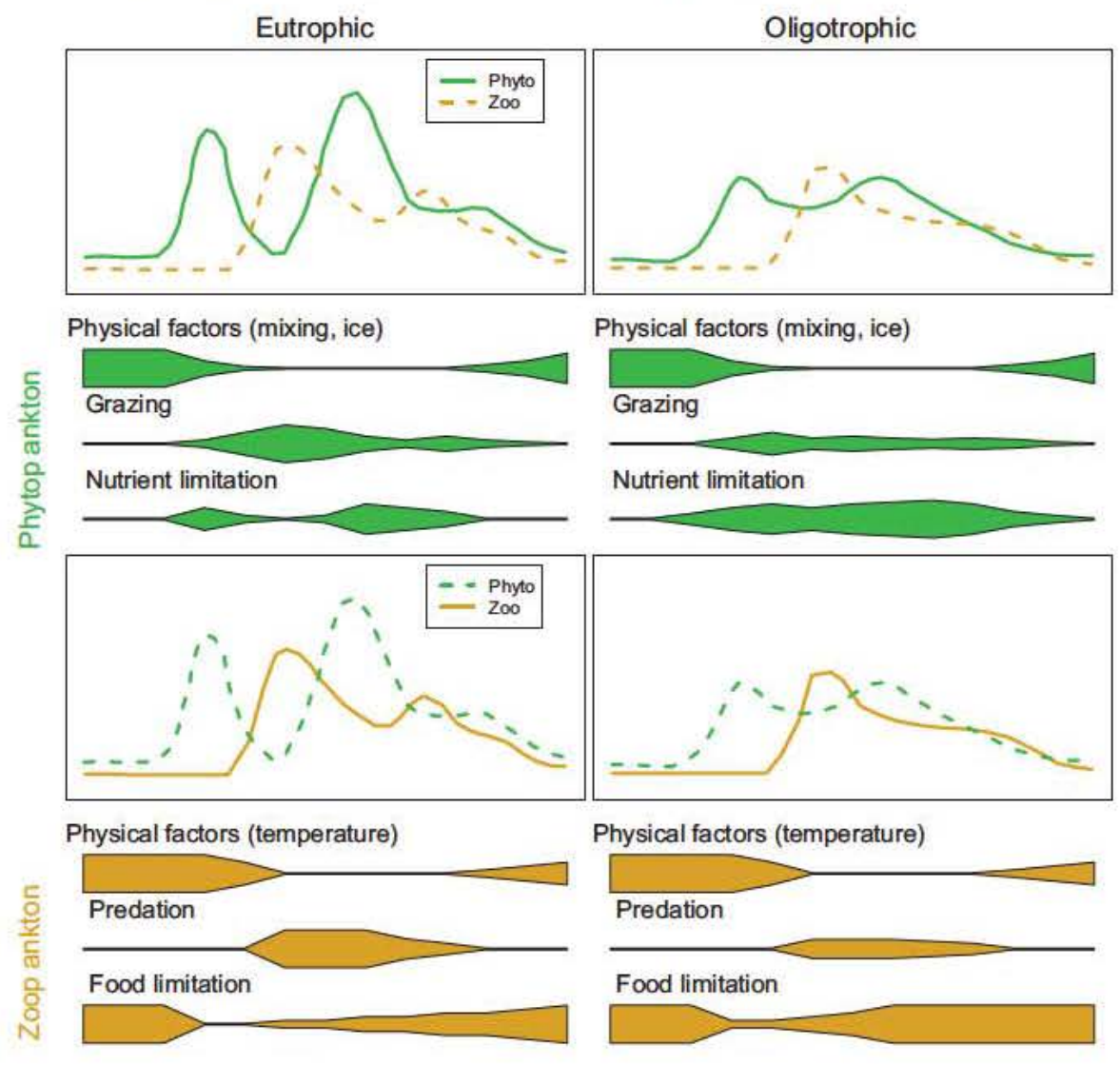


Blenckner \& Pettersson, 1999; Peeters et al., 2007). However, even in shallow ice-free lakes, zooplankton growth is likely to be limited by low temperatures during winter and spring.

In conclusion, comparative analysis of zooplankton seasonality between the (ultra-) oligotrophic, oligotrophic and eutrophic time periods of Lake Constance suggests that the PEG model's proposed differences in zooplankton biomass seasonality between eutrophic and oligotrophic lakes needs to be reconsidered. Furthermore, eutrophic and oligotrophic lakes in Sommer et al. (1986) differed also in altitude, likely resulting in erroneous attribution of temperature-induced seasonality differences between lake types to the trophic status of the lakes. This highlights the problem of confounding variables when analysing the influence of trophic status on plankton dynamics across different lakes. Analysis of plankton dynamics during different trophic conditions within one lake, that is a time-for-space substitution, is a powerful tool, as it allows for studying the influence of trophic status while keeping geographical setting and lake morphometry constant. However, even such studies need to consider the potential influence of confounding variables such as climate change. Despite the power of this approach, there is definitely a need for further studies involving many lakes and accounting for the confounding effects of, for example, lake altitude, latitude and climate change, to analyse to which extent the seasonal biomass trajectories of cladocerans and copepods from oligotrophic and eutrophic conditions of Lake Constance are typical for those in eutrophic and oligotrophic lakes in general.

\section{Acknowledgments}

I thank all people who contributed to the long-term data set of Lake Constance. Insightful comments by Ulrich Sommer and two reviewers improved the content of the manuscript. Funding was provided by the Deutsche Forschungsgemeinschaft (project STR 499/6-1).

\section{References}

Auerbach M., Maerker W. \& Schmalz J. (1924) Hydrographisch-biologische Bodensee-Untersuchungen. I. Ergebnisse der Jahre 1920-1922. Archiv für Hydrobiologie, 3, 538597.

Auerbach M., Maerker W. \& Schmalz J. (1926) Hydrographisch-biologische Bodensee-Untersuchungen II. Ergebnisse der Jahre 1923 und 1924 und Zusammenfassung 1920 1924. Verhandlungen des naturwissenschaftlichen Vereins in Karlsruhe, 30, 1129.
Berger S., Diehl S., Stibor H., Sebastian P. \& Scherz A. (2014) Separating effects of climatic drivers and biotic feedbacks on seasonal plankton dynamics: no sign of trophic mismatch. Freshwater Biology, 59, 22042220.

Berger S.A., Diehl S., Stibor H., Trommer G. \& Ruhenstroth M. (2010) Water temperature and stratification depth independently shift cardinal events during plankton spring succession. Global Change Biology, 16, 19541965.

Berger S.A., Diehl S., Stibor H., Trommer G., Ruhenstroth M., Wild A. et al. (2007) Water temperature and mixing depth affect timing and magnitude of events during spring succession of the plankton. Oecologia, 150, 643654 .

De Bernardi R. (1984) Methods for the estimation of zooplankton abundance. In: A Manual on Methods for the Assessment of Secondary Productivity in Fresh Waters. IBP Handbook 17 (Eds J.A. Downing \& F.H. Rigler), pp. 5986. Blackwell, Oxford.

De Senerpont Domis L.N., Elser J.J., Gsell A.S., Huszar V.L.M., Ibelings B.W., Jeppesen E. et al. (2013) Plankton dynamics under different climatic conditions in space and time. Freshwater Biology, 58, 463482.

Dodson S.I. (2004) Introduction to Limnology. McGraw-Hill, New York, USA.

Elster H.J. \& Einsele W. (1937) Beiträge zur Hydrographie des Bodensees [Obersee]. Internationale Revue der Gesamten Hydrobiologie, 35, 522585.

Geller W. (1986) Diurnal vertical migration of zooplankton in a temperate great lake (L. Constance): a starvation avoidance mechanism? Archiv für Hydrobiologie/Supplement, 74, 160.

George D.G. (2012) The effect of nutrient enrichment and changes in the weather on the abundance of Daphnia in Esthwaite Water, Cumbria. Freshwater Biology, 57, 360372.

Gillooly J.F. \& Dodson S.I. (2000) Latitudinal patterns in the size distribution and seasonal dynamics of new world, freshwater cladocerans. Limnology and Oceanography, 45, 230.

Güde H., Rossknecht H. \& Wagner G. (1998) Anthropogenic impacts on the trophic state of Lake Constance during the 20th century. Archiv für Hydrobiologie, Special Issues: Advances in Limnology, 53, 85108.

Jochimsen M.C., Kümmerlin R. \& Straile D. (2013) Compensatory dynamics and the stability of phytoplankton biomass during four decades of eutrophication and oligotrophication. Ecology letters, 16, 8199.

Lampert W., Fleckner W., Rai H. \& Taylor B.E. (1986) Phytoplankton control by grazing zooplankton: a study on the spring clear-water phase. Limnology and Oceanography, 31, 478490.

Lampert W. \& Sommer U. (1993) Limnoökologie. Thieme, Stuttgart.

Marshall C.T. \& Peters R.H. (1989) General patterns in the seasonal development of chlorophyll a for temperate lakes. Limnology and Oceanography, 34, 856867.

Muckle R. \& Muckle-Rottengatter G. (1976) Einige Tabellen und Bemerkungen zur Soziologie des Crustaceenplanktons 
im Überlinger See (Bodensee-Obersee). Archiv für Hydrobiologie, 78, 415455.

Nicolle A., Hallgren P., von Einem J., Kritzberg E.S., Granéli W., Persson A. et al. (2012) Predicted warming and browning affect timing and magnitude of plankton phenological events in lakes: a mesocosm study. Freshwater Biology, 57, 684695.

Pace M.L. (1986) An empirical analysis of zooplankton community size structure across trophic lake gradients. Limnology and Oceanography, 31, 4555.

Peeters F., Straile D., Lorke A. \& Ollinger D. (2007) Turbulent mixing and phytoplankton spring bloom development in a deep lake. Limnology and Oceanography, 52, 286298.

Reid J.W. \& Williamson C.E. (2010) Copepoda. In: Ecology and Classification of North American Freshwater Invertebrates, Third edit edn (Eds J.H. Thorp \& A.P. Covich), pp. 829 899. Academic Press, Boston, MA, USA.

Schalau K., Rinke K., Straile D. \& Peeters F. (2008) Temperature is the key factor explaining interannual variability of Daphnia development in spring: a modelling study. Oecologia, 157, 531543.

Seebens H., Einsle U. \& Straile D. (2009) Copepod life cycle adaptations and success in response to phytoplankton spring bloom phenology. Global Change Biology, 15, 13941404.

Seebens H., Einsle U. \& Straile D. (2013) Deviations from synchrony: spatio-temporal variability of zooplankton community dynamics in a large lake. Journal of Plankton Research, 35, 2232.

Seebens H., Straile D., Hoegg R., Stich H.B. \& Einsle U. (2007) Population dynamics of a freshwater calanoid copepod: complex responses to changes in trophic status and climate variability. Limnology and Oceanography, 52, 23642372.

Sommer U., Adrian R., De Senerpont Domis L., Elser J.J., Gaedke U., Ibelings B. et al. (2012) Beyond the Plankton Ecology Group (PEG) model: mechanisms driving plankton succession. Annual Review of Ecology, Evolution, and Systematics, 43, 429448.

Sommer U., Gliwicz Z.M., Lampert W. \& Duncan A. (1986) The PEG-model of seasonal succession of planktonic events in fresh waters. Archiv für Hydrobiologie, 106, 433471.

Straile D. (2000) Meteorological forcing of plankton dynamics in a large and deep continental European lake. Oecologia, 122, 4450.

Straile D. (2002) North Atlantic Oscillation synchronizes food-web interactions in central European lakes. Proceedings. Biological Sciences / The Royal Society, 269, 391395.

Straile D., Adrian R. \& Schindler D.E. (2012) Uniform temperature dependency in the phenology of a keystone herbivore in lakes of the Northern Hemisphere. PLoS ONE, 7, e45497.
Straile D. \& Geller W. (1998) Crustacean zooplankton in Lake Constance from 1920 to 1995: response to eutrophication and reoligotrophication. Archiv für Hydrobiologie, Special Issues: Advances in Limnology, 53, 255274.

Straile D., Jöhnk K.D. \& Rossknecht H. (2003) Complex effects of winter warming on the physicochemical characteristics of a deep lake. Limnology and Oceanography, 48, 14321438.

Straile D. \& Müller H. (2010) Response of Bosmina to climate variability and reduced nutrient loading in a large lake. Limnologica, 40, 9296.

Thienemann A. (1921) Biologische Seetypen und die Gründung einer hydrobiologischen Anstalt am Bodensee. Archiv für Hydrobiologie, 13, 347370.

Wagner A., Hülsmann S., Horn W., Schiller T., Schulze T., Volkmann S. et al. (2013) Food-web-mediated effects of climate warming: consequences for the seasonal Daphnia dynamics. Freshwater Biology, 58, 573587.

Wessels M., Mohaupt K., Kümmerlin R. \& Lenhard A. (1999) Reconstructing past eutrophication trends from diatoms and biogenic silica in the sediment and the pelagic one of Lake Constance. Journal of Paleolimnology, 21, 171192.

Wetzel R.G. (2001) Limnology Lake and River Ecosystems. Academic Press, San Diego.

Weyhenmeyer G.A., Blenckner T. \& Pettersson K. (1999) Changes of the plankton spring outburst related to the North Atlantic Oscillation. Limnology and Oceanography, 44, 17881792.

\section{Supporting Information}

Additional Supporting Information may be found in the online version of this article:

Figure S1. Crustacean biomass composition using species-specific dry masses and ignoring within-species dry mass information.

Figure S2. Seasonality of total crustacean biomass using species-specific dry masses and ignoring within-species dry mass information.

Figure S3. Seasonality of cladoceran and copepod biomass using species-specific dry masses and ignoring within-species dry mass information.

Figure S4. Seasonality of total crustacean biomass assuming underestimation of Hetercope biomass after June.

Figure S5. Sensitivity analysis of total crustacean biomass seasonality during the (ultra-) oligotrophic period in respect to species-specific sampling efficiencies. 